\title{
Novos rumos da preservação digital: das estratégias aos sistemas informatizados
}

\author{
Henrique Machado dos Santos \\ Universidade Federal do Rio Grande - FURG, Brasil \\ Daniel Flores \\ Universidade Federal de Santa Maria - UFSM, Brasil
}

REVIEW

\begin{abstract}
Resumo
Objetivo. Este estudo realiza uma breve reflexão sobre a preservação de documentos arquivísticos digitais, destacando a relação entre as políticas institucionais, as estratégias de preservação digital, e os sistemas informatizados de gestão e preservação.

Método. Consiste no levantamento bibliográfico de materiais previamente publicados das áreas de Arquivologia e Ciência da informação, resultando em um artigo de revisão assistemática. As fontes consultadas consistem em livros, teses, textos em sites da internet e artigos científicos de periódicos indexados no Google Scholar, com um recorte temporal referente aos últimos vinte anos.

Resultados. A literatura pesquisada conduz a necessidade de se definir, previamente, as políticas de preservação digital, e após, implementaros sistemas informatizados para gestão e preservação, mantendo altos níveis de interoperabilidade. Além disto, salienta-se a questão de manter uma cadeia de custódia ininterrupta que contemple as três idades do ciclo de vida dos documentos.

Conclusões. Este estudo sintetiza aspectos de um sistema de preservação digital gerido basicamente em duas etapas distintas, porém interoperáveis. Desta forma, reforça as discussões sobre a cadeia de custódia documental e interoperabilidade entre as normas, os sistemas informatizados e os demais softwares utilizados no acervo.
\end{abstract}

Palavras-chave

Documentos arquivísticos digitais; Interoperabilidade; Políticas institucionais; Preservação digital; RDC-Arq; SIGAD; Sistemas informatizados

\section{New directions of digital preservation: of the strategies to the computerized systems}

\begin{abstract}
Objective. This study makes a brief reflection on the preservation of digital records, highlighting the relationship between institutional policies, digital preservation strategies, and computerized systems of management and preservation.

Method. It consists of the lifting of bibliographic material previously published in the areas of Archival Science and Information Science, resulting in an unsystematic review article. Consulted sources consist of books, theses, texts on websites and scientific journal articles indexed in Google Scholar, with a time frame for the last twenty years.

Results. The literature leads to the need to define in advance the policies of digital preservation, and after, implementing computerized systems for management and preservation, maintaining high levels of interoperability. In addition, it is noted the issue of keeping an unbroken chain of custody covering the three ages of the document life cycle.

Conclusions. This study synthesizes aspects of a digital preservation system basically managed in two distinct stages, but interoperable. This reinforces the discussions on the chain of documentary custody and interoperability between standards, computerized systems and other software used in the collection.
\end{abstract}

\section{Keywords}

Computerized systems; Digital preservation; Digital records; Institutional policies; Interoperability; RDC-Arq; SIGAD 


\section{Introdução}

Os avanços das tecnologias da informação e a demanda por documentos digitais vêm configurando certo grau de dependência por estes formatos. Como consequência, os ciclos de obsolescência tecnológica tornam as atividades de preservação digital essenciais em um contexto cada vez mais incerto.

Para contornar os efeitos da obsolescência tecnológica e preservar documentos arquivísticos digitais em longo prazo, torna-se necessário definir políticas institucionais, implementar estratégias e sistemas informatizados. Considerando estas questões, este estudo pretende abordar inicialmente, as políticas institucionais em um escopo mais amplo, no qual são inseridos, posteriormente, as estratégias e os sistemas informatizados de gestão e preservação. Deste modo, tem-se por objetivo realizar uma reflexão sobre a preservação de documentos arquivísticos digitais, com ênfase na implementação de sistemas informatizados para gestão e preservação.

Para isto, utiliza-se uma metodologia baseada no levantamento bibliográfico de materiais previamente publicados, e esse artigo é caracterizado como de revisão assistemática. Desta forma, apresenta considerações sobre os sistemas informatizados para gestão e preservação de documentos arquivísticos digitais (GIL, 2010; LUNA, 1997; SILVA; MENEZES, 2005).

\section{A evolução do documento arquivístico frente à tecnologia da informação}

A evolução das tecnologias da informação, bem como a introdução de suas ferramentas no campo pragmático da Arquivística, incitou a produção de documentos digitais. Essa demanda é resultado da enorme facilidade para criar, editar, excluir, difundir e acessar as informações registradas em meio digital, culminando assim, na rápida disseminação destes novos registros.

As mudanças provocadas pelas tecnologias da informação implicam em realizar um longo processo de revisão dos princípios arquivísticos, sejam epistemológicos, sejam pragmáticos. Tal fato pode ser considerado um marco na trajetória da Arquivologia (RONDINELLI, 2005).

A presença de documentos produzidos e armazenados exclusivamente em formato digital reforça a existência de um patrimônio documental de natureza mista nos acervos, o qual é composto por documentos digitais e tradicionais. Observa-se que os documentos foram se modificando gradativamente, sempre sendo aperfeiçoados sob algum ponto de vista considerado relevante. Este aspecto é claramente delineado por Marcondes (2010) ao ressaltar que:

Documentos também devem ser considerados como condicionados tecnologicamente. [...] são unidades discretas de registro e transferência de mensagens; a aparente fluidez de limites dos documentos digitais hipertextuais, problemas de validade desses documentos, são decorrência do estágio tecnológico recente de desenvolvimento dos documentos digitais que logo serão superados pelo desenvolvimento tecnológico (MARCONDES, 2010, p. 11).

O fato dos documentos serem oriundos de uma tecnologia relativamente recente implica no desconhecimento de parte das suas potencialidades e principalmente, de suas vulnerabilidades. Sendo assim, é possível afirmar que a sociedade contemporânea vem produzindo documentos de valor histórico, social, informativo, cultural e científico, dos quais pode-senão ter perspectiva de longevidade. Logo, a grande ânsia desta questão é que documentos digitais vêm sendo produzidos em ritmo acelerado e as metodologias para preservação, como as estratégias e os sistemas informatizados, não estão acompanhando esta evolução, o que compromete o acesso e a presunção de autenticidade.

Por influência dos avanços das tecnologias da informação, o uso de formatos digitais (por exemplo, softwares e documentos digitais) expandiu-se para a sociedade como um todo, resultando em maior disponibilidade, diversidade e volume de dados (DE SORDI, 2008). Aliado a este fato, as novas perspectivas de negócios mediadas pela internet impulsionaram produção de documentos digitais armazenados e disseminados nos mais diversos suportes, em diferentes formatos e versões, representados na forma de texto, áudio, vídeo, imagem, bases de dados, etc.

A natureza digital expande o conceito de documento por si só, possibilitando diversos tipos de conteúdo e representações. Neste sentido Bodê (2007) destaca sua heterogeneidade, bem como sua materialidade: 
[...] com a utilização de documentos eletrônicos-digitais, dentro de arquivos de computador, estruturados em formatos de arquivo específicos, ocorre uma separação entre os suportes físicos e seus conteúdos. Os documentos em arquivos de computador, ainda precisam ser gravados em suportes físicos, no entanto, podem ser gravados em suportes diferentes em termos tecnológicos e inclusive é possível gerar várias cópias idênticas dos mesmos documentos em locais diferentes (BODÊ, 2007, p. 35).

Conforme apresentado, mesmo sendo fruto de uma "primorosa" evolução tecnológica, o documento digital, não se tornou um elemento virtual, que não ocupa espaço no Universo. Há necessidade de armazená-lo fisicamente através de suportes eletrônicos, como por exemplo, em um CompactDisc (CD). O que muda é a sua codificação, pois não há como ler diretamente um documento armazenado no $\mathrm{CD}$, sendo necessário, o periférico de acesso para realizar a leitura do CD, e o software capaz de interpretar o seu conteúdo.

Talvez esta seja a maior distinção entre o tradicional e o digital, a qual vem disseminando a ideia de que o documento digital é algo "virtuoso", até mesmo imaterial; o que ele não é! A ideia de abstração do documento digital, bem como a sensação de ruptura frente ao modelo tradicional, é condicionada à tecnologia da época, decorrente de um avanço natural. Sendo assim, ressalta-se que os bits que compõe um documento digital necessitam estar logicamente ordenados em uma linguagem, e fisicamente registrados em um suporte eletrônico, o qual é um objeto material.

\section{Documento arquivístico digital: demanda e fragilidade}

O surgimento, e a consequente demanda por tecnologias da informação acarretaram mudanças nos hábitos do público geral, de modo que estas mudanças se manifestam nos arquivos (RONDINELLI, 2005). Desta forma, pode-se destacar o surgimento do documento arquivístico digital que é resultado do registro da informação orgânica por intermédio de computadores. Deste modo, tornou-se necessário redefinir conceitos e criar teorias específicas para estes documentos.

Inegavelmente, os computadores são instrumentos que facilitaram o armazenamento, o tratamento e a recuperação das informações de modo geral. Porém, o uso inadequado destas ferramentas, com, por exemplo, inclusões, exclusões, e adulterações de documentos, comprometerão registros de relevância ímpar, resultando em lacunas nos acervos arquivísticos (PAES, 2004).

A tecnologia evoluiu em um ritmo muito acelerado, tendo grande aceitação e demanda por formatos digitais, principalmente nos setores relacionados à economia, administração e cultura. Tais fatos podem ser observados através do valor que a tecnologia da informação agrega para os negócios, ou seja, através da informação estratégica vista como um fator competitivo; da mesma, as tecnologias da informação podem representar a memória contemporânea, através dos documentos digitais dotados, por exemplo, de valor arquivístico.

Porém, a rápida expansão para o meio digital ocorreu sem mensurar os impactos que poderiam ser desencadeados pela própria tecnologia, o que vem colocando uma parte significativa da memória social em risco. Tal fato se justifica, pois inicialmente, o meio digital era tido como uma solução definitivamente, mas o tempo mostrou que os documentos digitais possuem mais vulnerabilidades quando comparados aos documentos em suportes analógicos, como o papel. Neste sentido, as falhas no planejamento de longo prazo e a insuficiência de conhecimentos sobre os possíveis impactos da obsolescência tecnológica estão fazendo gigantescas massas documentais, em formato digital, sucumbirem.

Observa-se que os documentos digitais possuem uma série de complexidades e especificidades. Dentre as complexidades, podem ser citadas a sua composição, a qual pode incluir diversos componentes digitais relacionados; a sua relação orgânica com os demais documentos; e o seu processo de tramitação. Já com relação as suas especificidades, destaca-se o aparato tecnológico de hardware e software necessários para correta representação.

Além das complexidades e especificidades, os documentos digitais são muito vulneráveis a obsolescência tecnológica, pois na medida em que surgem novas plataformas de hardware e/ou software surgem incompatibilidades dificultando o acesso a documentos produzidos em plataformas mais antigas (BRASIL, 2004; FERREIRA, 2006; INNARELLI, 2006). Sendo assim, podem ter a sua presunção de autenticidade facilmente questionada. Tais aspectos são evidenciados por meio da facilidade de alterar dados, excluir registros de 
maneira imperceptível se comparada aos registros tradicionais em suportes como o papel (BRASIL, 2004; 2011; 2012; CORRÊA, 2010; INTERPARES 2 PROJECT, 2007).

O documento arquivístico digital trouxe inegavelmente uma série de vantagens [...]. No entanto, se não houver procedimentos adequados de segurança e de preservação, a confiabilidade, a autenticidade e o acesso desses documentos ficam ameaçados e, portanto, eles não terão mais valor como prova das atividades (ROCHA; SILVA, 2007, p. 115).

No meio digital, há mudanças além do suporte, pois o documento se difere dos padrões conhecidos, dentre eles a leitura direta e a relação inseparável do suporte. Tudo é codificado em bits, desta forma, a leitura se dá por intermédio de softwares acessíveis por meio de computadores e igualmente codificados em bits (RONDINELLI, 2013). Por conseguinte, o documento digital está condicionado à tecnologia na qual foi criado, e esta tecnologia poderá se tornar obsoleta. Como resultado desta evolução incontrolável, há documentos de contextos tecnológicos diferentes, ou seja, em diferentes suportes e plataformas de hardware e software, que estão sendo produzidos e preservados em um mesmo acervo.

A demanda social e a consequente proliferação de documentos criados exclusivamente em formato digital ameaçam a capacidade de utilizar os arquivos como fontes confiáveis, isto se deve as incertezas com relação a sua preservação (THOMAZ, 2005). As fragilidades implícitas nos documentos digitais, como, por exemplo, a necessidade de um aparato tecnológico específico, e a capacidade de alterar e excluir sem deixar vestígios, denotam um fator de preocupação com a sua guarda em longo prazo. Neste sentido, questões como a manutenção da autenticidade, a garantia de acesso, bem como a correta interpretação, é fundamental para assegurar os valores informativos, históricos e sociais dos documentos.

O documento arquivístico digital vive em extremos, sua produção é tão simples enquanto a sua preservação ainda é abstrata. Não há "fórmulas mágicas", e sim um paradoxo: preservar os documentos que foram produzidos, os que estão sendo produzidos, ou, os que vão ser produzidos? Todos devem ser preservados! Entretanto, deve-se considerar o fato de que os documentos digitais estão ficando cada vez mais complexos, pois estão surgindo, por exemplo: novos formatos de arquivo; atualizações de software; novas plataformas de hardware; recursos de interatividade. A tecnologia não parou e nem vai parar de avançar, e desta forma, os softwares possuirão mais recursos e a diversidade de formatos e versões continuará aumentando.

A constante evolução das tecnologias da informação e dos documentos por elas produzidas acelera os ciclos de obsolescência tecnológica. Desta forma, os documentos precisam ser submetidos a um plano de preservação para definir estratégias e sistemas que realizem a manutenção de sua autenticidade, além de garantir o acesso ao seu conteúdo intelectual. Neste contexto, salienta-se a importância de realizar a manutenção de suas propriedades significativas, que são elementos de sua estrutura de apresentação considerados fundamentais, como, por exemplo, o alinhamento de um texto na página, ou o efeito de transição de slides. Logo, a implementação de estratégias de preservação e sistemas informatizados deverá considerar quais são as propriedades significativas que devem ser mantidas, para tal, estas propriedades devem ser definidas previamente nas políticas institucionais de preservação.

\section{Políticas institucionais para preservação digital}

A preservação digital em longo prazo envolve diversas variáveis, como, por exemplo, o planejamento minucioso, a tecnologia e orçamentos consideráveis. No entanto, esta complexidade tem desanimado as instituições que custodiam o patrimônio digital para as futuras gerações (SAYÃO, 2010). Percebe-se que há uma série de requisitos a serem contemplados, logo, este planejamento torna-se muito complexo e termina, por vezes, sendo descontinuado ou nem mesmo iniciado pelas instituições. Neste sentido Boeres e Cunha (2012) destacam que:

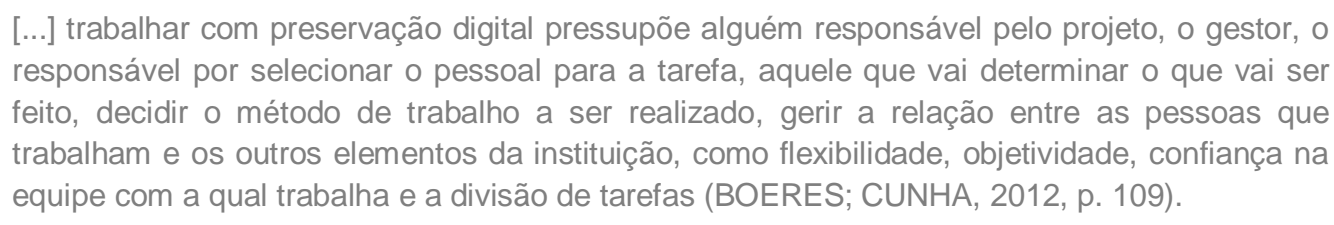

Além das normas, das tecnologias e da infraestrutura, também é preciso definir uma equipe de trabalho que deverá ter capacitação suficiente para realizar as atividades. Neste sentido, salienta-se a necessidade de uma equipe multidisciplinar frente ao setor de preservação, deste modo, será possível solucionar diversas lacunas no plano de preservação digital, sejam elas administrativas, arquivísticas, informáticas, etc. 
Quanto às políticas de preservação digital, observam-se questões pertinentes a serem definidas a priori, dentre estas, destacam-se:
a) Requisitos diplomáticos como os de forma fixa, conteúdo estável e variabilidade limitada;
b) As estratégias e os respectivos recursos tecnológicos (hardware, software e suporte) que serão utilizados;
c) A implementação do repositório digital;
d) Definição dos formatos de arquivo para preservação;
e) E a escolha dos padrões de metadados a serem utilizados.

Tendo em vista a conformidade com estes requisitos estima-se que será possível garantir questões como: garantia de acesso, autenticidade e confiabilidade aos documentos em custódia. Além disto, ressalta-se que a preservação de documentos digitais deve começar na sua produção, e não somente após sua submissão ao repositório digital. Assim será possível escolher os suportes, os softwares e os formatos de arquivo mais indicados para a preservação de longo prazo, como os padrões de jure ${ }^{1} \mathrm{e}$ de facto ${ }^{2}$.

De maneira geral, o corpus teórico de preservação digital vive uma constante transformação, porém, encontrase bastante limitado para propor uma solução aos problemas de obsolescência tecnológica. Não há uma solução definitiva, e sim um conjunto de estratégias, recomendações e padrões de formatos a serem considerados. Ressalta-se que este conjunto de soluções precisa evoluir, pois os documentos digitais continuarão sendo produzidos cada vez em maior volume, diversidade e complexidade.

Tendo em vista estas questões torna-se primordial que o responsável pela preservação de documentos digitais realize um planejamento prévio a fim de definir os investimentos necessários. Desta forma, observam-se três pilares fundamentais que são: as estratégias; os sistemas informatizados; e a interoperabilidade entre estratégias e sistemas. Estes três pontos devem estar em equilíbrio entre si e em conformidade com os requisitos que são definidos a priori nas políticas institucionais de preservação digital.

\section{Estratégias de preservação}

Tendo em vista a realidade digital dos acervos, pode-se afirmar que as estratégias de preservação se constituem como um meio fundamental para garantir a longevidade dos documentos digitais (MÁRDERO ARELLANO, 2008). Neste sentido, chama-se atenção para a escolha das estratégias a serem contempladas no plano de preservação digital.

A maioria dos estudos apresenta uma abordagem geral das estratégias, confrontando-as entre si, bem como reportando suas vantagens e desvantagens mais salientes. Dentre as estratégias, é possível destacar a preservação de tecnologia, o refrescamento, a emulação, o encapsulamento e a migração, as quais podem ser encontradas nos estudos de Corrêa (2010), Ferreira (2006), Grácio e Fadel (2010), Iglésia Franch (2008), Lopes (2008), Márdero Arellano (2004; 2008), Rothenberg (1999), Santos (2005), Saramago (2002), Thibodeau (2002) e Thomaz (2004).

Há também abordagens de caráter mais específico, discutindo a análise de uma determinada estratégia, o que permite resultados de maior precisão no que se refere a suas vantagens e desvantagens. Dentre estes, Granger (2000) apresenta uma análise sobre a emulação, enfatizando sua importância nos casos em que a aparência e os recursos de interatividade são considerados importantes. Outras estratégias, como, por exemplo, a migração, pode apresentar a perda destes aspectos. Além disso, a emulação em plataformas abertas se tornaria mais viável, sendo possível eliminar as restrições de uso do emulador mediante uma licença específica. No entanto, a diversidade de formatos de arquivo, cada vez mais complexos, desafia a capacidade dos emuladores o quais estariam em constante mudança para se adaptar a estes novos formatos. 
Já Ferreira, Baptista e Ramalho (2006) que abordam a migração, mais especificamente, a migração distribuída, uma estratégia que faz uso de serviços via web para ocultar a complexidade dos conversores. Com esta estratégia é possível desenvolver uma rede de conversões juntamente com outros preservadores, criando assim, novas operações de migração. Com este compartilhamento de serviços e de conhecimento, um documento digital pode ser submetido a diversos tipos de conversão, logo, o preservador terá diferentes resultados, podendo escolher o mais satisfatório.

Os estudos mencionados apontam que não há uma solução definitiva para o problema da preservação digital. No entanto, trazem diversas contribuições para contornar os efeitos da obsolescência tecnológica. Observa-se que o comparativo das estratégias de preservação digital permite vislumbrar diferentes contextos onde uma determinada estratégia será ou não recomendada. Além disto, os trabalhos que apresentam a análise de uma estratégia ressaltam complexidades e especificidades de sua implementação com maior riqueza de detalhes.

A conclusão mais impactante dos estudos de Corrêa (2010), Ferreira (2006), Ferreira, Baptista e Ramalho, (2006), Grácio e Fadel (2010), Granger (2000), Iglésia Franch (2008), Lopes (2008), Márdero Arellano (2004; 2008), Rothenberg (1999), Santos (2005), Saramago (2002), Thibodeau (2002) e Thomaz (2004), e que não deve ser ignorada, é que ainda não há uma estratégia que solucione todas as intempéries da preservação digital. E desta forma, as estratégias não podem ser implementadas de forma isolada. A aplicabilidade das estratégias dependerá do contexto tecnológico em que os documentos estão inseridos e do conhecimento disponível aos preservadores. Tais afirmações reforçam a necessidade de mais estudos sobre as estratégias e 0 seu papel dentro das políticas institucionais de preservação digital.

Em linhas gerais, as estratégias de preservação digital são essenciais à manutenção da integridade, da autenticidade, da garantia de acesso e correta interpretação dos documentos digital no longo prazo. No entanto, a sua implementação necessita de uma lógica que oriente seus procedimentos para garantir a autenticidade documental; registrando os métodos e as ferramentas empregadas no tratamento dos documentos arquivísticos e seus respectivos componentes digitais.

\section{Sistemas informatizados para custódia documental}

Para preservar documentos digitais autênticos será necessário implementar sistemas informatizados que considerem suas complexidades e especificidades para garantir a confiabilidade da custódia. Logo, estes sistemas devem seguir padrões voltados à gestão de documentos (THIBODEAU, 2002). Estes sistemas precisam contemplar uma ampla variedade de formatos de arquivo, realizar a manutenção destes formatos e proporcionar acesso aos usuários (HEDSTROM, 1998).

Tanto os sistemas de gestão, quanto os de preservação devem possuir mecanismos que garantam a integridade e a autenticidade dos documentos armazenados. Além disso, ressalta-se a necessidade de se manter uma cadeia de custódia ininterrupta, a qual agregará maior confiabilidade à documentação custodiada.

Considerando a complexidade e a especificidade dos documentos arquivísticos, deve-se chamar a atenção para o fator da autenticidade em meio digital. Desta forma, ressalta-se a sua facilidade de adulteração:

Os documentos arquivísticos digitais apresentam dificuldades adicionais para presunção de autenticidade em razão de serem facilmente duplicados, distribuídos, renomeados, reformatados ou convertidos, além de poderem ser alterados e falsificados com facilidade, sem deixar rastros aparentes (BRASIL, 2012, p.1).

Os documentos arquivísticos em meio digital possuem vulnerabilidades implícitas visto que podem ser facilmente falsificados ou excluídos, por isto, encontram-se em um risco contínuo durante a sua trajetória. Logo, é essencial que se implementem políticas e estratégias de preservação digital, sendo geridas por sistemas informatizados.

Neste sentido, os sistemas informatizados de gestão e preservação contribuem para um gerenciamento em alto nível da documentação, monitorando e registrando todas as atividades. Assim, o Conselho Nacional de Arquivos preconiza a adoção de um Sistema Informatizado de Gestão Arquivística de Documentos (SIGAD) o qual poderá ser um software ou um conjunto de softwares responsáveis por contemplar a gestão dos documentos arquivísticos em fase corrente e intermediária (BRASIL, 2014; 2015). 
Através do SIGAD será possível garantir questões como: o controle do ciclo de vida; o cumprimento da destinação final (eliminação ou guarda permanente); a sua relação orgânica; as características fundamentais previamente definidas; e a manutenção da autenticidade (BRASIL, 2014; 2015). Ressalta-se que o SIGAD deve contemplar o conjunto de normas pré-estabelecidas nas políticas de arquivo para gestão de documentos. Este conjunto de normas compreende, por exemplo, os formatos de arquivo que serão utilizados na produção dos documentos e os padrões de metadados. Sua pertinência se fundamenta na necessidade de manter a autenticidade dos documentos em fase corrente e intermediária.

A definição de políticas institucionais deverá estabelecer os requisitos para realizar a manutenção da integridade e da autenticidade dos documentos digitais. Estas são questões a serem consideradas antes de se implementar qualquer software, seja ele um SIGAD ou um RDC-Arq.

[...] deve-se ter claro que documentos devem ser capturados e em que momento isso deve ocorrer. Isto implica na definição de critérios quanto à classificação e à avaliação dos documentos arquivísticos digitais. Para isso, os arquivistas devem realizar um diagnóstico institucional e arquivístico que abranja a identificação e hierarquização das funções, atividades e rotinas da instituição e contemple os documentos necessários ao registro e à comprovação da execução dessas atividades (SANTOS, 2005, p. 148-149).

Para a construção de um SIGAD recomenda-se estabelecer a conformidade com o e-ARQ Brasil, "Modelo de Requisitos para Sistemas Informatizados de Gestão Arquivística de Documentos”. Este modelo visa orientar a gestão de documentos arquivísticos, seja em formato digital ou tradicional. Além de fornecer especificações técnicas, funcionais e metadados os quais deverão ser considerados na aquisição ou no desenvolvimento do SIGAD (BRASIL, 2011). Ressalta-se que o modelo e-ARQ foi desenvolvido pelo Conselho Nacional de Arquivos, órgão vinculado ao Arquivo Nacional do Brasil, e vem sendo abordado em alguns estudos publicados em língua portuguesa dos quais podem ser citados: Silva e Bedin (2014), Schäfer e Lima (2012) e Aganette, Teixeira e Almeida (2015).

Por conseguinte, os documentos armazenados no SIGAD são recolhidos ao repositório digital, o qual deverá contemplar a fase permanente, completando assim o ciclo de vida documental. Ao repositório competem as funções de preservar documentos digitais autênticos, e proporcionar o acesso em longo prazo de modo que estes documentos sejam corretamente interpretados pelos usuários.

Para o repositório digital, recomenda-se a implementação do Open Archival Information System (OAIS) que é um modelo de referência conceitual. $O$ fato de ser um modelo teórico torna as possibilidades de aplicação do OAIS mais amplas, visto que o repositório digital pode ser desenvolvido através de diferentes plataformas de hardware e software, desde que contemplem os requisitos do OAIS. Dentre estes requisitos, podem ser citados, por exemplo, os pacotes de informação, as entidades funcionais e os serviços de apoio.

Tendo em vista a perspectiva de efetividade do modelo OAIS, o Arquivo Nacional do Brasil, por meio de seu órgão vinculado, o Conselho Nacional de Arquivos, desenvolveu a resolução $\mathrm{n}^{\circ}$ 39, posteriormente alterada pela resolução n ㄴ 43, a qual define a implementação do Repositório Arquivístico Digital Confiável (RDC-Arq) para transferir e recolher os documentos arquivísticos digitais para instituições arquivísticas de órgãos e entidades vinculadas ao Sistema Nacional de Arquivos (BRASIL, 2014; 2015).

Sendo assim, o processo de preservação dos documentos deve começar na fase corrente, desta forma, ressalta-se a importância da implementação de um SIGAD para garantir a fidedignidade dos documentos. Observa-se que a fidedignidade não pode ser "criada", ela precisa ser preservada durante todo o ciclo documental. Para isto, os documentos armazenados nos SIGAD's e nos RDC-Arq's devem ser mantidos em uma custódia confiável. Nestes ambientes, toda e qualquer alteração realizada sobre os documentos digitais e seus respectivos componentes precisa ser registrada através de metadados para que seu histórico seja capaz de mensurar sua autenticidade. Logo, é fundamental integrar o SIGAD ao RDC-Arq proporcionando uma linha de custódia ininterrupta.

Destaca-se que a implementação de um sistema de gestão e um de preservação, de forma distinta, faz uma divisão da cadeia de custódia. Desta forma, os documentos de valor corrente e intermediário,são armazenados no SIGAD, e os documentos de valor permanente,armazenados no RDC-Arq. Tal divisão não deve ser entendida como uma ruptura, pois há necessidade destes sistemas interoperarem a fim de possibilitar que os documentos armazenados no SIGAD sejam transferidos/recolhidos ao RDC-Arq. Desta forma, destaca-se que a interoperabilidade entre os sistemas informatizados deve ser considerada na definição das políticas de 
preservação, a fim de facilitar a transferência dos documentos que estão armazenados no SIGAD para o RDCArq; formando assim, uma linha de custódia ininterrupta.

Neste ponto, chama-se a atenção para uma questão contemporânea: a mudança da cadeia de custódia. Ao se recolher a documentação dos sistemas de gestão para os de preservação também é possível que haja uma mudança do responsável pela preservação em longo prazo. Desta forma, deve-se verificar a integridade e a autenticidade dos documentos no momento da transferência/recolhimento ao RDC-Arq. Após isto, a responsabilidade por manter os documentos fidedignos passa a ser exclusivamente do preservador.

Nos casos em que não houver mudança da cadeia de custódia, a responsabilidade será do detentor do acervo, que é simultaneamente produtor e preservador da autenticidade de seus documentos. Entretanto, para adicionar confiabilidade aos seus métodos de preservação e manutenção da autenticidade, a instituição, seja ela custodial ou pós-custodial, deverá realizar auditorias periódicas seguidas por atividades de certificação realizada por instituição competente para tal, a fim de comprovar ao longo do tempo que preserva documentos de maneira confiável. A auditoria é realizada em um primeiro estágio para verificar a conformidade do repositório digital com o modelo OAIS e com requisitos de ordem tecnológica e organizacional pré-estabelecidos (INTERPARES 2 PROJECT, 2007).

Estas auditorias podem ser internas ou externas, dentre as internas, pode-se destacar o Digital Repository Audit Method Basedon Risk Assessment (DRAMBORA). Com este documento é possível identificar as vulnerabilidades do repositório a fim de retificá-las e submeter posteriormente à auditoria externa.

Dentre os modelos de auditoria externa podem ser citados: Trustworthy Repository Audit \& Certification: Criteria and Checklist (TRAC); Audit And Certification of Trustworthy Digital Repositories (ACTDR); e Catalogue of Criteria for Trusted Digital Repositories da Network of Expertise in long-term STORage (NESTOR). Cada um destes documentos possui um conjunto de critérios para mensurar a confiabilidade dos repositórios digitais e posteriormente, proceder à certificação.

De maneira geral, os sistemas de gestão e preservação devem ser planejados de forma que todos os seus requisitos sejam definidos previamente nas políticas de preservação digital. Logo, destaca-se a importância de políticas institucionais que definam requisitos técnicos e níveis de interoperabilidade entre metodologias de trabalho, padrões de metadados e estratégias de preservação.

\section{A interoperabilidade entre sistemas de gestão e preservação}

Após a definição de uma política de preservação digital e a respectiva escolha das ferramentas de gestão e preservação, a equipe multidisciplinar deverá proceder à implementação do sistema documental como um todo. Casanovas (2008) ressalta a necessidade de se trabalhar com sistemas informatizados que sejam interligados. Neste sentido, a interoperabilidade entre os sistemas de gestão e preservação é considerada um fator primordial para o ciclo documental, potencializando as atividades da instituição.

Um repositório digital deve estar em conformidade com as normas e padrões estabelecidos, de forma a possibilitar níveis de interoperabilidade com outros repositórios digitais e sistemas informatizados que tratam de documentos arquivísticos (BRASIL, 2015, p. 11).

Ao se falar em interoperabilidade deve-se considerá-la entre os repositórios, atuando como um fator colaborativo das instituições responsáveis pela custódia de materiais digitais com valor cultural. Práticas como esta atuam como fator colaborativo, onde é possível trocar experiências entre diferentes repositórios.

A capacidade de interoperar é facilitada com o uso de padrões abertos o que pode abranger colaboradores internacionais em uma rede a fim de minimizar a redundância dos serviços, bem como os custos de manutenção (MÁRDERO ARELLANO, 2008). Além disso, o compartilhamento de padrões de metadados enriquecerá a interoperabilidade entre os repositórios (SARAMAGO, 2002).

Outra questão da interoperabilidade é manifestada no nível interno do RDC-Arq, ou seja, é a capacidade de interação entre as ferramentas e as normas utilizadas. Neste sentido, pode-se citar a relação entre o ciclo de vida dos documentos, onde o SIGAD, o qual deve estar em conformidade com o e-ARQ Brasil, será responsável pelas fases corrente e intermediária; já o RDC-Arq, deverá estar em conformidade com o OAIS, e será responsável pela fase permanente, conforme observado na resolução no 39 (BRASIL, 2014) ratificada pela resolução no 43 (BRASIL, 2015), ambas do Conselho Nacional de Arquivos. Neste contexto, a capacidade de 
interoperar influencia diretamente a qualidade da transferência e do recolhimento. Isto reforça a necessidade de se conhecer as especificidades das plataformas de hardware e software, dos suportes e das normas que são utilizados no acervo.

No âmbito interno do acervo, além da interação entre SIGAD e RDC-Arq, deve-se considerar a interoperabilidade entre o RDC-Arq e as estratégias de preservação digital. Em outras palavras, o RDC-Arq, enquanto ambiente confiável deverá facilitar a implementação de estratégias de preservação, como, por exemplo, a migração, o refrescamento, o encapsulamento, a emulação, entre outras que sejam possíveis (BRASIL, 2014; 2015).

Observa-se que a implementação de estratégias de preservação continua sendo fundamental para garantir o acesso em longo prazo, e desta forma, o RDC-Arq atua na gestão dos métodos de preservação. Logo, é preciso manter níveis de interoperabilidade entre o RDC-Arq e determinadas estratégias para garantir a preservação de documentos autênticos em longo prazo.

É fundamental que um RDC-Arq auxilie nas atividades de refrescamento, pois na transferência de documentos de um suporte qualquer para o RDC-Arq será preciso inserir metadados; e deve-se considerar que o refrescamento é uma estratégia de caráter genérico, visto que é aplicável a documentos armazenados em todos os tipos de suportes. Desta forma, no momento da submissão dos documentos digitais, o RDC-Arq deverá exigir a inserção de metadados no padrão definido previamente pelo administrador do sistema.

No caso do encapsulamento, o RDC-Arq pode corroborar reunindo os materiais necessários para a representação fidedigna do documento encapsulado. Desta forma, todos os componentes digitais que compreendem o documento arquivístico deverão ficar em custódia do RDC-Arq.

Ao se proceder a emulação de documentos, é pertinente registrar no RDC-Arq qual é o software emulador utilizado, bem como qualquer alteração deste software. Observa-se a importância de metadados que registrem o histórico dos documentos arquivísticos, e que assim auxiliam na compreensão do seu contexto de preservação.

Nas atividades de migração é essencial que o RDC-Arq implemente metadados para registrar as mudanças de versão e de formato dos documentos e de seus respectivos componentes digitais. Da mesma forma é de interesse registrar quais os conversores utilizados para estas atividades, bem como um mecanismo que informe a existência de erros no procedimento de migração. Além disso, o RDC-Arq deverá ser capaz de retroceder ao objeto inicial, ou seja, restaurar a versão do documento anterior caso ocorra uma conversão malsucedida.

Em linhas gerais, a interoperabilidade do RDC-Arq não se restringe à comunicação e troca de experiência com outros RDC-Arq's da rede. Interoperar é ter procedimentos compatíveis com os objetivos da política institucional de preservação, de modo que os requisitos não se oponham as funcionalidades dos sistemas, e que assim, o produto das estratégias não seja distorcido com relação ao que foi definido previamente na política institucional. Desta forma, a interoperabilidade entre estratégias, políticas institucionais, SIGAD e RDC-Arq potencializa as atividades de preservação, as quais poderão ser gerenciadas em alto nível, o que facilita a identificação de possíveis erros nos procedimentos.

\section{Considerações finais}

Este estudo realizou uma reflexão sobre os sistemas informatizados de gestão e preservação. Para isto, foram perpassadas questões como: os impactos das tecnologias da informação; o surgimento do documento arquivístico digital, as políticas institucionais; e as estratégias de preservação.

Observa-se que o advento do documento arquivístico digital tornou necessário o desenvolvimento de um processo de reformulação dos conceitos de preservação, bem como a presunção de autenticidade. Tal fato vem gerando diversos estudos, e assim, constituindo uma bibliografia especializada sobre o tema.

Os documentos digitais estão condicionados às tecnologias, caso haja uma evolução, torna-se necessária uma adaptação. A obsolescência de um formato torna necessária a adoção de outro, o mesmo acontece no caso dos softwares. No mundo das tecnologias o acervo deve estar aberto a transformações, sejam elas políticas, tecnológicas ou mesmo financeiras. Logo, a capacidade de adaptação frente às novas tecnologias torna-se fundamental para salvaguardar o patrimônio documental para as gerações futuras.

Após a reflexão sobre as políticas institucionais, as estratégias e os sistemas informatizados, apontam-se questões pertinentes como a interoperabilidade e a manutenção de uma cadeia de custodia ininterrupta. Logo, é 
fundamental estabelecer níveis de interoperabilidade entre o SIGAD, as estratégias e o RDC-Arq a fim de atingir os objetivos definidos nas políticas institucionais de preservação digital. Tais fatos corroboram para a manutenção da cadeia de custódia, pois os sistemas informatizados de gestão e preservação precisam estar interligados de modo que possibilite a transferência/recolhimento da documentação que está no SIGAD para o RDC-Arq. Desta forma, ressalta-se, com pertinência, a necessidade dos acervos das instituições brasileiras estabelecerem a conformidade do SIGAD com o modelo e-ARQ Brasil, e a conformidade do RDC-Arq com o modelo OAIS.

Em resumo, os estudos sobre preservação digital são fundamentais para garantir a longevidade do patrimônio registrado em dígitos binários. As estratégias de preservação digital e os sistemas informatizados se implementados de forma isolada não fornecerão garantias de acesso em longo prazo. Tal fato ressalta a importância de se definirem previamente as políticas institucionais de preservação para desenvolver um sistema de preservação digital sincronizado, mesmo assim, ainda há necessidade de estudos interdisciplinares que explorem o potencial das estratégias, dos sistemas informatizados e das políticas institucionais.

Por fim, este estudo contribui para compreender os desafios da implementação de um sistema de preservação digital gerido em duas etapas distintas e interoperáveis, o SIGAD e o RDC-Arq. Os pontos perpassados reforçam a discussão sobre a manutenção de uma cadeia de custódia documental ininterrupta, bem como a necessidade de se manterem níveis de interoperabilidade entre as normas e as tecnologias utilizadas no acervo. Dentre suas limitações, observa-se que as recomendações se restringem às recomendações do Arquivo Nacional do Brasil, no caso o modelo e-ARQ e as resoluções no 39 (BRASIL, 2014) e n 43 (BRASIL, 2015). Mesmo assim, este artigo poderá fornecer uma base teórica para estudos que envolvam a relação entre os sistemas informatizados de gestão e preservação, pois considera padrões arquivísticos sem entrar profundamente nas peculiaridades brasileiras.

\section{Referências}

AGANETTE, Elisangela; TEIXEIRA, Lívia; ALMEIDA, Maurício. A prática arquivística e a gestão do conteúdo organizacional: relato de experiência em empresa do setor energético. Tendências da Pesquisa Brasileira em Ciência da Informação, Belo Horizonte, v. 8, n. 1, p. 85-105, jan./juh. 2015. Disponível em: <http://inseer.ibict.br/ancib/index.php/tpbci/article/view/181>. Acesso em 25 set. 2016.

BODÊ, Ernesto Carlos. Preservação de acervos documentais eletrônicos. Revista Brasileira de Arqueometria, Restauração e Conservação. Olinda, v.1, n.2, 2007, p. 32-35. Disponível em: <http://www.restaurabr.org/siterestaurabr/volumesarc/arc02pdf/07preservacaodeacervos.pdf>. Acesso em: 15 dez. 2014.

BOERES, Sonia Araújo de Assis; CUNHA, Murilo Bastos da. Competências básicas para os gestores de preservação digital. Ciência da Informação, Brasília, v. 41 n. 1, p.103-113, jan./abr., 2012. Disponível em: $<$ http://revista.ibict.br/index.php/ciinf/article/view/2115>. Acesso em: 01 abr. 2015.

BRASIL. CONSELHO NACIONAL DE ARQUIVOS. Câmara Técnica de documentos eletrônicos. Carta para a Preservação do Patrimônio Arquivístico Digital. Rio de Janeiro: Arquivo Nacional, 2004. Disponível em: $<$ http://www.conarq.arquivonacional.gov.br/Media/publicacoes/cartapreservpatrimarqdigitalconarq2004.pdf>. Acesso em: 10 ago. 2014.

BRASIL. CONSELHO NACIONAL DE ARQUIVOS. Câmara Técnica de documentos eletrônicos. Diretrizes para a presunção de autenticidade de documentos arquivísticos digitais. Rio de Janeiro: Arquivo Nacional, 2012. Disponível em: $<$ http://www.conarq.arquivonacional.gov.br/media/diretrizes presuncao autenticidade publicada.pdf >. Acesso em: 20 jun. 2014.

BRASIL. CONSELHO NACIONAL DE ARQUIVOS. Câmara Técnica de documentos eletrônicos. Diretrizes para a implementação de repositórios digitais confiáveis de documentos arquivísticos. Rio de Janeiro: Arquivo Nacional, 2014. Disponível em: <http://www.conarq.arquivonacional.gov.br/media/publicacoes/resol conarq 39 repositorios.pdf $>$. Acesso em: 13 ago. 2015

BRASIL. CONSELHO NACIONAL DE ARQUIVOS. Câmara Técnica de documentos eletrônicos. Diretrizes para a implementação de repositórios arquivísticos digitais confiáveis - RDC-Arq. Rio de Janeiro: Arquivo Nacional, 2015. Disponível em: <http://www.conarq.gov.br/images/publicacoes textos/diretrizes rdc arq.pdf>. Acesso em: 10 jun. 2016.

BRASIL. CONSELHO NACIONAL DE ARQUIVOS. Câmara Técnica de documentos eletrônicos. e-ARQ Brasil: Modelo de Requisitos para Sistemas Informatizados de Gestão Arquivística de Documentos. Rio de Janeiro: Arquivo Nacional, 2011. Disponível em:

$<$ http://www.conarq.arquivonacional.gov.br/media/publicacoes/earq/conarq earqbrasil model requisitos 2009.pdf >. Acesso em: 05 ago. 2014.

CASANOVAS, Inés. Gestión de documentos electrónicos. Buenos Aires: Alfagrama, 2008. 
CONSULTATIVE COMMITTEE FOR SPACE DATA SYSTEM (CCSDS). Reference Model for an Open Archival Information System (OAIS). Magenta Book. Washington, Jun. 2012. Disponível em:

<http://public.ccsds.org/publications/archive/650x0m2.pdf>. Acesso em: 13 mai. 2014

CORRÊA, Amarílis Montagnolli Gomes. Preservação digital: autenticidade e integridade de documentos em bibliotecas digitais de teses e dissertações. Dissertação (Mestrado em Ciência da Informação) 96 p. Universidade de São Paulo, São Paulo, 2010. Disponível em: <http://www.teses.usp.br/teses/disponiveis/27/27151/tde-05112010-105831/pt-br.php>. Acesso em: 03 jul. 2014.

DE SORDI, José Osvaldo. Administração da informação: fundamentos e práticas para uma nova gestão do conhecimento. São Paulo: Saraiva, 2008

FERREIRA, Miguel. Introdução à preservação digital: conceitos, estratégias e atuais consensos, Portugal: Escola de Engenharia da Universidade do Minho, 2006. Disponível em:

<https://repositorium.sdum.uminho.pt/bitstream/1822/5820/1/livro.pdf>. Acesso em: 02 ago. 2014

FERREIRA, Miguel; BAPTISTA, Ana Alice; RAMALHO, José Carlos. A Foundation for Automatic Digital Preservation. Ariadne: Web Magazine for InformationProfessionals, 2006. Disponível em: <http://www. ariadne.ac.uk/issue48/ferreiraetal>. Acesso em 10 Jan. 2015

GIL, Antonio Carlos. Como elaborar projetos de pesquisa. 5. Ed. São Paulo: Atlas, 2010.

GRÁCIO, José Carlos Abbud; FADEL, Bárbara. Estratégias de preservação digital.In: VALENTIM, Marta (org.) Gestão, mediação e uso da informação. São Paulo: UNESP: Cultura Acadêmica, 2010. Disponível em: $<$ http://livros.universia.com.br/download/Livros Academicos/Gestao mediacao e uso da informacao.pdf>. Acesso em: 01 dez. 2014.

GRANGER, Stewart. Emulation as a Digital Preservation Strategy.D-Lib Magazine, v. 6, n. 10, 2000.Disponível em: $<$ http://www. dlib.org/dlib/october00/granger/10granger.html>. Acessoem: 24 jun. 2015

HEDSTROM, Margareth. Digital preservation: a time bomb for digital libraries. Computer and the humanities, Netherlands, $\mathrm{n}$. 31, p. 189-202, 1998. Disponível em: <http://deepblue.lib.umich.edu/bitstream/2027.42/42573/1/105792004 Article 153071.pdf>. Acessoem: 01 out. 2014.

IGLÉSIA FRANCH, David. La fotografia digital en los archivos: qué es y como se trata. Ediciones TREA, 2008, España.

INNARELLI, Humberto Celeste. Preservação de documentos digitais: confiabilidade de mídias CD-ROM e CD-R. 174p. 2006. Dissertação (Mestrado) - Faculdade de Engenharia Mecânica, Universidade Estadual de Campinas, Campinas, 2006. Disponível em: <http://www. bibliotecadigital.unicamp.br/document/?code=vtls000384479>. Acesso em: 06 jun. 2014.

INTERPARES 2 PROJECT. Diretrizes do Preservador. A preservação de documentos arquivísticos digitais: diretrizes para organizações. TEAM Brasil. Tradução: Arquivo Nacional e Câmara dos Deputados. 2002-2007. Disponível em: <http://www.interpares.org/display file.cfm?doc=ip2 preserver guidelines booklet--portuguese.pdf>. Acesso em: 09 ago. 2014

LOPES, Vitor. Preservação Digital. Portugal: Universidade do Minho, Guimarães, 2008. Disponível em: <http://www.vitorlopes.com/Trabalhos/Preservacao Digital-Vitor Lopes.pdf>. Acesso em: 28 ago. 2012.

LUNA, Sergio Vasconcelos de. Planejamento de pesquisa: uma introdução. São Paulo: EDUC, 1997.

MARCONDES, Carlos Henrique. Linguagem e documento: fundamentos evolutivos e culturais da Ciência da Informação. Perspectivas em Ciência da Informação, Belo Horizonte, v. 15, n. 2, p 2-21, maio./ago. 2010. Disponível em: $<$ http://portaldeperiodicos.eci.ufmg.br/index.php/pci/article/view/1019>. Acesso em: 10 fev. 2015.

MÁRDERO ARELLANO, Miguel Ángel. Preservação de documentos digitais, Ciência da Informação, Brasília, v. 33, n. 2, p. 15-27, maio/ago. 2004. Disponível em: <http://revista.ibict.br/ciinf/index.php/ciinf/article/view/305>. Acesso em: 25 jul. 2014.

MÁRDERO ARELLANO, Miguel Ángel. Critérios para a preservação digital da informação científica. 354 p. Tese (Doutorado em Ciência da Informação). Universidade Federal de Brasília, Departamento de Ciência da Informação, 2008. Disponível em: <http://bdtd.bce.unb.br/tedesimplificado/tde busca/arquivo.php?codArquivo=4547>. Acesso em: 15 Jun. 2014.

PAES, Marilena Leite. Arquivo: teoria e prática. 3. Ed. Rev. Ampl. Rio de Janeiro: FGV, 2005.

ROCHA, Claudia Lacombe; SILVA, Margareth da. Padrões para Garantir a Preservação e o Acesso aos Documentos Digitais. Acervo, Rio de Janeiro, v. 20, n. 1-2, p. 113-124, jan/dez 2007. Disponível em: <http://www.revistaacervo.an.gov.br/seer/index.php/info/article/view/142>. Acesso em: 07 set. 2014.

RONDINELLI, Rosely Curi. Gerenciamento arquivístico de documentos eletrônicos: uma abordagem teórica da diplomática arquivística contemporânea. 4. Ed. Rio de Janeiro: FGV, 2005.

RONDINELLI, Rosely Curi. O documento arquivístico ante a realidade digital: uma revisão conceitual necessária. Rio de Janeiro: FGV, 2013. 
ROTHENBERG, Jeff. Avoiding technological quicksand: finding a viable technical foundation for digital preservation. Commission on Preservation and Access and Council on Library and Information Resources: a report to the Council on Library and Information Resources. EUA: Washington, DC, 1999. Disponível em: <http://www.clir.org/pubs/reports/rothenberg/pub77.pdf>. Acesso em: 24 set. 2014

SANTOS, Vanderlei Batista dos. Gestão de documentos eletrônicos: uma visão arquivística. 2. Ed. Rev. Aum. Brasília: ABARQ, 2005

SARAMAGO, Maria de Lurdes. Preservação digital a longo prazo: boas práticas e estratégias. Cadernos BAD, Lisboa, 2002, n 2, p. 54-68. Disponível em: <http://www.bad.pt/publicacoes/index.php/cadernos/article/view/866>. Acesso em: 10 fev. 2015.

SAYÃO, Luis Fernando. Uma outra face dos metadados: informações para a gestão da preservação digital. Encontros Bibli: R. Eletr. Bibliotecon. Ci. Inf., Florianópolis, v. 15, n. 30, p.1-31, 2010. Disponível em: $<$ https://periodicos.ufsc.br/index.php/eb/article/view/1518-2924.2010v15n30p1>. Acesso em: 10 fev. 2015.

SCHÄFER, Murilo Billig; LIMA, Eliseu dos Santos. A classificação e a avaliação de documentos: análise de sua aplicação em um sistema de gestão de documentos arquivísticos digitais. Perspectivas em Ciência da Informação, v. 17, n. 3, p. 137-154 jul./set. 2012. Disponível em: <http://portaldeperiodicos.eci.ufmg.br/index.php/pci/article/view/1477>. Acesso em 25 set. 2016.

SILVA, Edna Lúcia da; MENEZES, Estera Muszkat. Metodologia da pesquisa e elaboração de dissertação. 4. Ed. rev. atual. Florianópolis: UFSC, 2005. Disponível em:

$<$ https://projetos.inf.ufsc.br/arquivos/Metodologia de pesquisa e elaboracao de teses e dissertacoes 4ed.pdf >. Acesso em: 13 jun. 2014.

SILVA, Suéllem Chrystina Leal da; BEDIN, Sonali PaulaMolin. Sistemas de gestão documental em Florianópolis: análise de funcionalidades baseada nos requisitos do E-ARQ Brasil. Ágora, Florianópolis, v. 24, n. 48, p. 298-331, mar. 2014. Disponível em: <https://agora.emnuvens.com.br/ra/article/view/493>. Acessoem: 25 set. 2016.

THIBODEAU, Kenneth. Overview of Technological Approaches to Digital Preservation and Challenges in Coming Years: The State of Digital Preservation: An International Perspective. Anais eletrônicos... Washington: CLIR and Library ofCongress, 2002. Disponível em: <http://www.clir.org/pubs/reports/pub107/thibodeau.html>. Acesso em: 19 ago. 2014.

THOMAZ, Kátia de Pádua. A preservação de documentos eletrônicos de caráter arquivístico: novos desafios, velhos problemas. 389 p. Tese (Doutorado em Ciência da Informação). Escola de Ciência da Informação. Universidade Federal de Minas Gerais, 2004. Disponível em: <http://www.bibliotecadigital.ufmg.br/dspace/bitstream/handle/1843/VALA68ZRKF/doutorado katia de padua thomaz.pdf>. Acesso em: 28 jul. 2014.

THOMAZ, Kátia de Pádua. Documentos eletrônicos de caráter arquivístico: fatores condicionantes da preservação. Perspectivas em Ciência da Informação, Belo Horizonte, v.10 n.1, p. 34-53, jan./jun. 2005. Disponível em: $<$ www.brapci.ufpr.br/download.php?dd0=13204>. Acesso em: 07 set. 2014. 


\section{Dados dos autores}

Henrique Machado dos Santos

Mestrando em Patrimônio Cultural pela Universidade Federal de Santa Maria. Arquivista da Universidade Federal do Rio Grande - FURG.

henrique.hms.br@gmail.com

\section{Daniel Flores}

Doutor em Documentação pela Universidade de Salamanca. Professor Adjunto do Departamento de Documentação da Universidade Federal de Santa Maria - UFSM.

dfloresbr@gmail.com

Recebido - Received: 2016-06-09

Aceitado - Accepted: 2018-01-09

1 São formatos aprovados e regulamentados por um órgão competente como a International Organization for Standartization (ISO).

2 São formatos que não foram aprovados por órgão regulamentador, porém são amplamente utilizados em escala global.

\section{(cc) EY}

This work is licensed under a Creative Commons Attribution 4.0

United States License.

\section{ULLS D-Sorke}

This journal is published by the University Library System of the University of Pittsburgh as part of its $\underline{D-S c r i b e}$ Digital Publishing Program and is cosponsored by the University of Pittsburgh Press. 